\title{
Yanıt Yüzey Metodolojisi Şartlarında Karabaş Otu Yağının Kompleks Koaservasyon Yöntemi İle Enkapsülasyonu
}

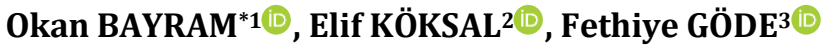 \\ 1,2Süleyman Demirel Üniversitesi, Fen Bilimleri Enstitüsü, Kimya Bölümü, 32000, Isparta, Türkiye \\ ${ }^{3}$ Süleyman Demirel Üniversitesi, Fen Edebiyat Fakültesi, Kimya Bölümü, 32000, Isparta, Türkiye
}

(Alınış / Received: 12.02.2020, Kabul / Accepted: 02.08.2020, Online Yayınlanma / Published Online: 20.08.2020)

\author{
Anahtar Kelimeler \\ Karabaș otu, \\ Kompleks koaservasyon, \\ Enkapsülasyon, \\ Mikro teknoloji, \\ Nano teknoloji.
}

Özet: Çalışmamızda karabaş otu yağı yanıt yüzey metodolojisi (YYM) ile oluşturulan bir deney setinde kompleks koaservasyon yöntemi ile enkapsülasyon yapılmıştır. Deney seti YYM'e üç bağımsız değişken (çekirdek maddesi miktarı, surfaktan konsantrasyonu, karıştırma hızı) girilerek oluşturulmuştur. Üretilen numunelerden enkapsülasyon verimi (\%EV) hesaplanmıştır. Bulunan deneysel verimler YYM'e cevap yanıtı olarak girilerek analiz edilmiştir. YYM analizi sonucunda ulaşılan model önemlidir $(\mathrm{p}<0,05), \mathrm{R}^{2}$ değeri \%99,15, uyum eksikliğinin p değeri 0,217 ( $p>0,05$ ) bulunmuştur. Elde edilen verilerden YYM'e girilen üç bağımsız değişkenin cevap yanıtı olan \%EV'yi etkilediği sonucuna ulaşılmıştır. Deney setinden üretilen numuneler optik mikroskop ve taramalı elektron mikroskobu (SEM) altında karakterize edilmiştir. Elde edilen görüntülerde kapsüller, büyük çoğunluğu mikron $\left(10^{-6}\right)$, az miktarda nano $\left(10^{-9}\right)$ boyutunda gözlenmiştir. Yapılan çalışmanın kullanım alanlarının geniş, ekonomik değeri yüksek olan karabaş otu yağının enkapsülasyonunda ve farklı uygulama alanlarında değerlendirilmesinde önemli bir adım olacağı düşünülmektedir.

\section{Encapsulation of Karabas Herb Oil with Complex Coacervation Method in Response Surface Methodology Conditions}

\section{Keywords}

Karabas herb,

Complex coacervation,

Encapsulation,

Micro technology,

Nano technology.

\begin{abstract}
In our study, encapsulation was performed with complex coacervation method in an experimental set created with Karabas herb oil response surface methodology (RSM). The experiment set was created by entering three independent variables (core material amount, surfactant concentration, stirring speed) in RSM. The encapsulation efficiency (EV\%) was calculated from the produced samples. The experimental efficiencies found were analyzed by entering $\mathrm{RSM}$ as a response response. The model reached as a result of RSM analysis was significant ( $\mathrm{p}<0,05), \mathrm{R}^{2}$ value was $99,15 \%$, and lack-of-fit $\mathrm{p}$ value was found as $0,217(p>0,05)$. The collected data indicated that three independent variables entered in RSM affect the response response EV\%. Samples produced from the experimental set were characterized under optical microscope and scanning electron microscope (SEM). The vast majority of the images obtained were observed in micron $\left(10^{-6}\right)$ and a small amount of nano $\left(10^{-9}\right)$ in size. It is believed that the study will be an important step in the encapsulation of karabas herb oil, which has a wide range of economic value, and different application areas.
\end{abstract}

\section{Giriş}

Çalışmamızda karabaș otu yağı, yanıt yüzey metodolojisi kullanılarak oluşturulan deney setinde kompleks koaservasyon yöntemi ile enkapsülasyonlanmıştır. Enkapsülasyon verimi hesaplanarak istatistiksel analiz yapılmıştır. Optik mikroskop ve taramalı elektron mikroskobu ile üretilen mikrokapsüller karakterize edilmiștir. Çalışmamız kompleks koaservasyonla yapılacak enkapsülasyon işleminde yanıt yüzey metodolojisi yardımı ile oluşturulacak deney setinin sonuçlara etkisini istatistiksel olarak araştırmaktadır. $\mathrm{Bu}$ da ileride yapılacak çalışmalar için deneysel 
tasarım açısından literatüre fayda sağlayacaktır. Ayrıca deneysel tasarımla birlikte elde edilecek sonuçlar üretilen enkapsülasyon ürünlerinin farklı uygulamalarda kullanılmasında ve deney tasarımının oluşturulmasında yardımcı olacaktır.

Lavandula cinsi Lamiaceae ailesine aittir ve birçok türden oluşur. Lavandula cinsinin farklı türleri Türkiye dâhil birçok Akdeniz ülkesinde yetiştirilmektedir [1, 2]. Türkiye'de genellikle karabaş otunun L. stoechas ve L. stoechas ssp. cariensis türleri yetiştirilmektedir. L. stoechas, çalı tipi, dayanıklı, çok yıllık, koyu mor çiçekleri olan ve 45-50 cm yüksekliğinde olan endemik bir bitkidir [3-5]. Karabaş otu geniş kullanım alanlarına sahiptir. Bunlardan biri kozmetik ve parfüm sanayisidir [6-8]. Yapılan bir çalışmada antibakteriyel aktiviteye sahip karabaş otu esansiyel yağı ile yapılan masaj uygulamasının doğum sonrası yara iyileşmesinde etkili olduğu ortaya koyulmuştur. $[9,10]$. Yapılan bașka bir çalıșmada, organik domateslerden izole edilen $V$. dahliae mikroorganizmalarına karşı etkili bir biyofungisit olduğu ortaya koyulmuştur [11]. Diğer bir çalışmada ise karabaş otu yağı, bazı bakterilere karşı antibakteriyel etki göstermiştir [1214]. Literatürdeki diğer çalışmalar ışı̆̆ında karabaş otu yağının geniş kullanım alanına sahip önemli bir esansiyel yağ olduğu sonucuna ulaşılmıştır.

Bir çekirdek maddesinin enkapsülasyonu için kullanılan birçok kimyasal ve fiziksel enkapsülasyon yöntemi vardır. Koaservasyon, kontrollü şartlar altında ortam değişikliği ile indüklenen ilişkisel faz ayırma işlemini belirtmek için kullanılan bir terimdir. Koaservasyon basit ve kompleks olarak ikiye ayrılır [15]. Kaplanan malzemeye çekirdek maddesi, materyali vb. denilmektedir ve sıvı, gaz veya katı olabilir. Kaplama malzemesine ise duvar maddesi, materyali vb. denilmektedir [16]. Bu çalışmada karabaş otu yağının enkapsülasyonu için kompleks koaservasyon yöntemi kullanılmıştır. Kompleks koaservasyon ile kapsüllerin oluşumu, polimer konsantrasyonu ve oranına, $\mathrm{pH}$, sıcaklık gibi bazı faktörlere bağlıdır [17,18].

Yanıt yüzey metodolojisi (YYM), farklı girdi faktörlerinin bir veya daha fazla çıktı yanıtlarını nasıl etkilediğini ortaya çıkarmak için kullanılan deney tasarımlarından biridir [19]. Bu çalışmamızda kompleks koaservasyonu etkileyebilecek üç faktör seçilmiştir. Bunlar; çekirdek maddesi miktarı, surfaktan konsantrasyonu ve karıştırma hızıdır. Bu üç farklı değişkenin, kompleks koaservasyon ile hazırlanan enkapsülasyon aktivitesi üzerine etkisi yanıt yüzey metodolojisi kullanılarak belirlenmesi amaçlanmıştır. Çalışmada kullanılan deneysel tasarımın ve birlikte üretilen karabaș otu yağı içeren mikrokapsüllerin ileride kozmetik, gıda gibi alanlarda kullanılabileceği düșünülmektedir. Deney tasarımının amacl, gereksiz tekrarlardan kaçınarak ekonomik ve hızlı bir sonuca ulaşabilmektir.

\section{Materyal ve Metot}

\subsection{Deneysel tasarım}

Karabaş otu yağının enkapsülasyonundaki deneysel tasarım, yanıt yüzey metodolojisi aracılığıyla üç bağımsız değişken ile tasarlanmıştır. Tasarımın oluşturulmasında CCD (merkezi kompozit tasarım) kullanılmıştır. Tasarıma girilen değişkenler; (A) 3g-7g çekirdek maddesi miktarı, (B) 0,3\%-0,7\% a/h surfaktan konsantrasyonu ve (C) 1000rpm-2000rpm aralığında karıștırma hızıdır. Deney tasarımı, MINITAB 16 (Geçerlilik Tarihi: Süresiz) yazılımı kullanılarak yapılmıştır.

\subsection{Deneysel aşamada kullanılan kimyasal malzemeler}

Deneysel aşamada hazırlanan ve kullanılan kimyasallar Tablo 1'de gösterilmiştir.

Tablo 1. Kullanılan kimyasallar

\begin{tabular}{|c|c|c|}
\hline Materyal & Marka & Bazı Özellikleri \\
\hline Jelatin & Merck & $\% 12,5 \mathrm{a} / \mathrm{h}$ \\
\hline Arap Zamkı & Merck & $\% 12,5 \mathrm{a} / \mathrm{h}$ \\
\hline $\begin{array}{ll}\text { Sodyum } & \text { dodesil } \\
\text { sülfat (SDS) }\end{array}$ & Merck & $\begin{array}{l}\% 0,5 \mathrm{a} / \mathrm{h} \\
\text { HLB Değeri: } 40\end{array}$ \\
\hline Glutaraldehit & Merck & $\% 10 \mathrm{~h} / \mathrm{h}$ \\
\hline Asetik Asit & Merck & $\% 10 \mathrm{~h} / \mathrm{h}$ \\
\hline Sodyum Hidroksit & Merck & $\% 10 \mathrm{a} / \mathrm{h}$ \\
\hline Karabaș Otu Yağl & & $\begin{array}{l}\text { Üretim Yöntemi: Su } \\
\text { buharı distilasyonu }\end{array}$ \\
\hline
\end{tabular}

\subsection{Karabaş otu yağının GC analizi}

Ticari olarak satılan ve piyasadan temin edilen karabaş otu yağına GC analizi yapılmıştır. Kullanılan cihaz Shimadzu GC- 2010 Plus ve kullanılan dedektör Shimadzu GCMS-QP2010 SE'dür.

\subsection{Kompleks koaservasyon yöntemi ve enkapsülasyon}

Kimyasal enkapsülasyon işlemi kompleks koaservasyon yöntemi ile yapılmıştır. Tüm deneyler aynı sıcaklıkta yapılmıştır $\left(55^{\circ} \mathrm{C}\right)$. Çekirdek maddesi olarak kullanılan karabaş otu yağının etrafına kapsül duvarı jelatin ve Arap zamkı karışımı ile oluşturulmuştur. Öncelikle jelatin $(\% 12,5 \mathrm{a} / \mathrm{h})$ ve karabaş otu yağı 15 dakika karıştırılmıştır. Daha sonra çözeltiye sırasıyla SDS $(\% 0,5 \mathrm{a} / \mathrm{h})$ ve Arap zamkı (\%12,5 a/h) eklenerek 15'er dakika daha karıştırılmıştır. Çözeltideki jelatin/Arap zamkı oranı 1:1'dir. Daha sonra karışımın pH'ı asetik asit (\%10 $\mathrm{a} / \mathrm{h}$ ) ile $\mathrm{pH}=4$ 'e getirilmiştir. Karıșıma daha sonra glutaraldehit $(\% 10 \mathrm{~h} / \mathrm{h})$ eklenmiş ve çapraz bağlanma sağlanmıştır. Sonraki aşamada ise karışımın bulunduğu ısıtıcı kapatılarak yaklaşık 300 $\mathrm{mL}$ soğuk deiyonize su eklenmiş ve karıșımın ani soğuması sağlanmıştır. Karışım 3 saat süre ile karıştırıldıktan sonra sodyum hidroksit (\%10 a/h) ile $\mathrm{pH}=9,5$ olacak şekilde tekrar ayarlanmıştır. Elde 
edilen karışım oda sıcaklı̆̆ında bir gün bekletilmiştir. Bir gün sonra süzülerek yıkama, kurutma, tartım, boyut ölçümü gibi işlemler yapılmıștır. Yıkama işlemi ile numunede kalan safsızlıkların giderilmesi amaçlanmıştır [20].

\subsection{Karabaş otu yağı içeren kapsüllerin karakterizasyonu}

Deneysel aşamada üretilen kapsüller fiziksel yöntemlerle çözeltilerinden ayrılmıştır. Daha sonra optik mikroskop (Bueco BM-2000) ve SEM (QuantaTM 250 FEG) cihazları altında incelenmiștir. Yapılan bu işlem üretilen kapsüllerin boyutu, yapısı, şekli ve morfolojik yapısı hakkında bilgiler vermiştir. Optik mikroskop altında inceleme yapılırken numuneler iki cam lamel arasina ince bir tabaka halinde koyulmuştur. SEM altında inceleme yapılırken tek cam lamel üzerine çok ince bir tabaka halinde yayılarak görüntüler elde edilmiştir. Numunelere kaplama yapılmamıştır. SEM görüntülerinin hepsi kabin içi 60 pA - 70 pA basınç altında alınmıştır. Numunelerin iletkenliğini sağlamak için düşük vakum modu kullanılmış ve içeri eser miktarda su molekülleri gönderilmiștir.

\subsection{Enkapsülasyon verimi}

Deneysel tasarım ile birlikte üretilen numunelerden elde edilen mikrokapsüllerin enkapsülasyon verimliliği benzer çalışmalardan yararlanılarak oluşturulan denklem 1 yardımı ile hesaplanmıştır. Denklemdeki $\% \mathrm{EV}$, enkapsülasyon verimini, yüzey yağı miktarı ise kurutulan numunede bulunan enkapsüle edilememiş karabaș otu yağı miktarını temsil etmektedir.

$$
\% E V=\frac{\text { Toplam Yağ Miktarı }- \text { Yüzey Yağı Miktarı }}{\text { Toplam Yağ Miktarı }} \times 100
$$

Hazırlanan farklı kapsül numunelerindeki toplam yağ miktarı hesaplanırken, literatürdeki benzer çalışmalara göre $1 \mathrm{~g}$ kurutulmuş kapsül numunesi tartılmış ve $50 \mathrm{~mL}$ n-hekzan çözücü içeren erlen şişelerine eklenmiştir. n-hekzan içerisindeki numune 1 gün boyunca çalkalanmış ve çözelti filtre kâğıdı yardımı ile süzülmüștür. Daha sonra n-hekzan rotary evaporatör yardımı ile buharlaştırılmıştır. Yüzey yağı miktarı literatürdeki benzer çalışmalardan yola çlkarak; 50 mL n-hekzan içeren bir erlen şişesine $1 \mathrm{~g}$ kapsül numunesi koyulmuş ve karıșım, kapsül yıkımı olmadan ve yapisı bozulmadan 10 dakika boyunca hafifçe çalkalanmıştır. Daha sonra çözelti süzgeç kâğıdı ile süzülmüş ve n-hekzan rotary evaporatör kullanılarak buharlaştırılmıştır. Yüzeyde bulunan karabaş otu yağı miktarı ve toplam karabaş otu yağı miktarı gravimetrik olarak hesaplanmıștır. Bu işlemler deney setindeki tüm deneyler için tekrarlanmış ve hesaplamaları yapılmıştır [21-27].

\section{Bulgular}

\subsection{Karabaş otu yağının GC analizi sonuçları}

GC analiz sonuçlarında karabaş otu yağının GC kromatogramı Şekil 1'de gösterilmiştir.

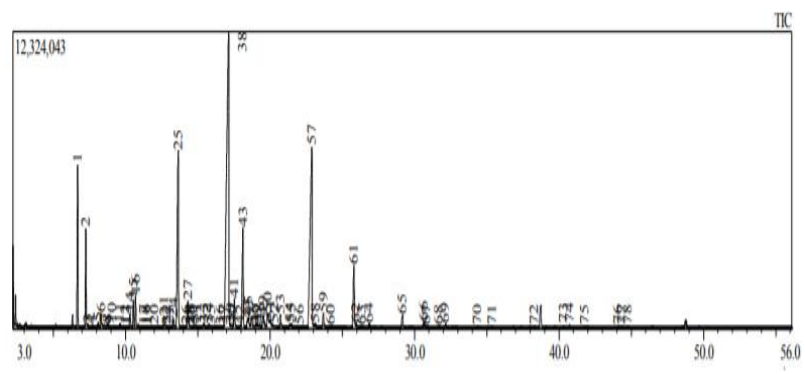

Şekil 1: Karabaş otu yağının GC kromatogramı

Kromatogramdaki büyük alanlı bileşikler Tablo 2'de verilmiştir. GC sonuçları literatürdeki çalışmalarla benzer bulunmuştur [28,29].

Tablo 2. GC analizi sonuçları

\begin{tabular}{lcc}
\multicolumn{1}{c}{ Bileşik } & $\begin{array}{c}\text { Alıkonma } \\
\text { Süresi }\end{array}$ & \%Alan \\
\hline$\alpha$-Pinen & 6,686 & 5,78 \\
Kampen & 7,255 & 3,62 \\
Fençon & 13,642 & 11,40 \\
Kâfur & 17,139 & 35,02 \\
p-Menthan-3-one, & 18,124 & 5,74 \\
(1R,4R)-(+)- & & \\
Isopulegone & 22,889 & 18,72 \\
Bornil asetat & 25,804 & 3,63 \\
\hline
\end{tabular}

\subsection{Enkapsülasyon Aşamasının Deneysel Tasarımla Optimizasyonu}

Karabaş otu yağının enkapsülasyon koşulları için deneysel çalışmalar yanıt yüzey metodolojisi ile üç bağımsız değişken yardımı ile oluşturulmuştur. YYM yardımı ile üç faktörlü ve yirmi adetlik deney seti elde edilmiştir. Üç değişken kimyasal bir yöntem olan kompleks koaservasyonu deneysel olarak etkileyebilecek değişkenlerden seçilmiştir. Bu faktörler sırasıyla; çekirdek maddesi miktarı $(3,00000 \mathrm{~g}-7,00000 \mathrm{~g})$, surfaktan konsantrasyonu $(\% 0,300000 \mathrm{a} / \mathrm{h}-\% 0,700000 \mathrm{a} / \mathrm{h})$ ve karıștırma hızı (1000,00 rpm - 2000,00 rpm) şeklindedir. Yirmi adet deney için belirtilen koşullar altında hesaplanan deneysel verimler belirlenmiş ve YYM'e eklenerek analiz edilmiştir. Hesaplama sonucunda elde edilen eşitlik denklem 2'de verilmiștir. Denklemde çekirdek maddesi miktarı (A), surfaktan konsantrasyonu (B), karıştırma hızı (C) ile gösterilmiştir.

\%Enkapsülasyon Verimi $=-51,2927+10,3481 \mathrm{~A}-$ $51,6789 \mathrm{~B}+0,0955016 \mathrm{C}-1,10901 \mathrm{~A}^{*} \mathrm{~A}+5,32970 \mathrm{~B}^{*} \mathrm{~B}$ $-0,0000281669 C^{*} \mathrm{C}+6,49688 A^{*} \mathrm{~B}-0,00118125 \mathrm{~A}^{*} \mathrm{C}$ $+0,0248125 \mathrm{~B}^{*} \mathrm{C}$

YYM'de oluşturulan deney seti, deneysel verim miktarları ve analiz sonucunda elde edilen denkleme göre hesaplanan verim miktarları birlikte Tablo 3'te 
verilmiştir. Tablo 3'te A; çekirdek maddesi miktarını g cinsinden, B; surfaktan konsantrasyonunu \%a/h cinsinden, C; karıștırma hızını rpm cinsinden, \%DV; yüzde deneysel verimi, $\% \mathrm{HV}$; yanıt yüzey metodolojisinden elde edilen denklem yardımıyla hesaplanan (tahmin edilen) yüzde verimi belirtmektedir.

Tablo 3. Karabaş otu yağının enkapsülasyonu için yanıt yüzey yöntemi ve sonuçları

\begin{tabular}{lccccc}
$\#$ & A (g) & B (\%a/h) & C (rpm) & \%DV & \%HV \\
\hline 1 & 5,00000 & 0,836359 & 1500,00 & 61,51 & 62,54 \\
\hline 2 & 7,00000 & 0,700000 & 2000,00 & 63,25 & 61,60 \\
\hline 3 & 5,00000 & 0,500000 & 1500,00 & 54,32 & 54,08 \\
\hline 4 & 3,00000 & 0,700000 & 2000,00 & 56,21 & 55,83 \\
\hline 5 & 7,00000 & 0,300000 & 2000,00 & 42,36 & 42,10 \\
\hline 6 & 5,00000 & 0,500000 & 1500,00 & 52,21 & 54,08 \\
\hline 7 & 7,00000 & 0,300000 & 1000,00 & 32,89 & 31,93 \\
\hline 8 & 5,00000 & 0,500000 & 1500,00 & 55,64 & 54,08 \\
\hline 9 & 8,36359 & 0,500000 & 1500,00 & 43,12 & 44,00 \\
\hline 10 & 5,00000 & 0,163641 & 1500,00 & 45,98 & 46,83 \\
\hline 11 & 5,00000 & 0,500000 & 1500,00 & 53,59 & 54,08 \\
\hline 12 & 1,63641 & 0,500000 & 1500,00 & 38,07 & 39,06 \\
\hline 13 & 5,00000 & 0,500000 & 1500,00 & 54,29 & 54,08 \\
\hline 14 & 5,00000 & 0,500000 & 2340,90 & 47,22 & 48,88 \\
\hline 15 & 7,00000 & 0,700000 & 1000,00 & 41,23 & 41,50 \\
\hline 16 & 3,00000 & 0,300000 & 2000,00 & 48,34 & 46,72 \\
\hline 17 & 5,00000 & 0,500000 & 659,10 & 19,23 & 19,45 \\
\hline 18 & 5,00000 & 0,500000 & 1500,00 & 54,78 & 54,08 \\
\hline 19 & 3,00000 & 0,700000 & 1000,00 & 32,09 & 31,00 \\
\hline 20 & 3,00000 & 0,300000 & 1000,00 & 31,52 & 31,82 \\
\hline & & & & &
\end{tabular}

Tablo 3 incelendiğinde oluşturulan deney setinden elde edilen deneysel verimler ile yanıt yüzey metodolojisinden elde edilen denklem ile hesaplanan verim değerleri arasındaki fark genellikle küçük bulunmuştur. Elde edilen deneysel sonuçların durumunu ve önemli değişkenlerini belirlemek için ANOVA testi yapılmıştır. Yapılan ANOVA testinin sonuçları Tablo 4'te gösterilmiştir.

Yapılan analiz sonucunda ulaşılan model önemlidir $(p<0,05)$. Model $(p<0,05)$ doğrusallık göstermektedir. A (çekirdek maddesi miktarl, p<0,05), B (surfaktan konsantrasyonu, $\mathrm{p}<0,05), \mathrm{C}$ (karıștırma hızl, $\mathrm{p}<0,05$ ) doğrusallık göstermektedir. Modelde kare önemlidir $(\mathrm{p}<0,05)$ ve $A^{*} \mathrm{~A} \quad\left(\mathrm{p}_{\mathrm{A}^{*} \mathrm{~A}}<0,05\right)$ ve $\mathrm{C}^{*} \mathrm{C} \quad\left(\mathrm{p}_{\left.\mathrm{C}^{*} \mathrm{C}<0,05\right)}\right.$ kareleri önemli iken $B^{*} B\left(p_{B} *_{B}=0,588\right)$ karesinde bir önemlilik göstermemektedir. Modelde iki yönlü etkileşim ( $\mathrm{p}_{\mathrm{A}^{*} \mathrm{~B}}<0,05, \mathrm{p}_{\mathrm{A}^{*} \mathrm{C}}<0,05, \mathrm{p}_{\left.\mathrm{B}{ }^{*} \mathrm{C}<0,05\right)}$ önemlidir. Uyum eksikliğinin $p$ değeri 0,217 (p>0,05) bulunmuştur. Uyum eksikliği değerinin $p>0,10$ olması veriyle modelin uyuştuğunu göstermektedir. $\mathrm{R}^{2}$ değeri 99,15\% bulunmuştur. Artıkların dağılımı incelenmiş ve yapılan normallik testi grafiği Şekil 2'de gösterilmiştir.
Tablo 4. Karabaș otu yağının enkapsülasyon ișleminden elde edilen YYM sonuçları için ANOVA sonuçları

\begin{tabular}{|c|c|c|c|c|c|c|}
\hline & $\begin{array}{l}\mathbf{s} \\
\mathbf{d}\end{array}$ & $\begin{array}{c}\text { Ardışık } \\
\text { Kareler } \\
\text { Toplam } \\
\text {, }\end{array}$ & $\begin{array}{c}\text { Kareler } \\
\text { Toplam } \\
\quad 1\end{array}$ & $\begin{array}{c}\text { Kareler } \\
\text { Ortalama } \\
\text { S1 }\end{array}$ & $\begin{array}{c}\text { F- } \\
\text { Değer } \\
\mathbf{i}\end{array}$ & $\begin{array}{c}\text { P- } \\
\text { Değer } \\
\mathbf{i}\end{array}$ \\
\hline Model & 9 & 2428,33 & 2428,33 & 269,81 & $\begin{array}{c}129,0 \\
9\end{array}$ & 0,000 \\
\hline Doğrusal & 3 & 1373,12 & 1373,12 & 457,71 & $\begin{array}{c}218,9 \\
9\end{array}$ & 0,000 \\
\hline A & 1 & 29,47 & 29,47 & 29,47 & 14,10 & 0,004 \\
\hline B & 1 & 297,94 & 297,94 & 297,94 & $\begin{array}{c}142,5 \\
5\end{array}$ & 0,000 \\
\hline $\mathrm{C}$ & 1 & 1045,71 & 1045,71 & 1045,71 & $\begin{array}{c}500,3 \\
1\end{array}$ & 0,000 \\
\hline Kare & 3 & 940,77 & 940,77 & 313,59 & $\begin{array}{c}150,0 \\
4\end{array}$ & 0,000 \\
\hline$A^{*} \mathrm{~A}$ & 1 & 214,05 & 283,59 & 283,59 & $\begin{array}{c}135,6 \\
8\end{array}$ & 0,000 \\
\hline $\mathrm{B}^{*} \mathrm{~B}$ & 1 & 12,12 & 0,65 & 0,65 & 0,31 & 0,588 \\
\hline $\mathrm{C}^{*} \mathrm{C}$ & 1 & 714,60 & 714,60 & 714,60 & $\begin{array}{c}341,9 \\
0\end{array}$ & 0,000 \\
\hline $\begin{array}{l}\text { 2-Yönlü } \\
\text { Etkileșim }\end{array}$ & 3 & 114,44 & 114,44 & 38,15 & 18,25 & 0,000 \\
\hline$A * B$ & 1 & 54,03 & 54,03 & 54,03 & 25,85 & 0,000 \\
\hline$A^{*} C$ & 1 & 11,16 & 11,16 & 11,16 & 5,34 & 0,043 \\
\hline $\mathrm{B}^{*} \mathrm{C}$ & 1 & 49,25 & 49,25 & 49,25 & 23,56 & 0,001 \\
\hline Hata & $\begin{array}{l}1 \\
0\end{array}$ & 20,90 & 20,90 & 2,09 & & \\
\hline $\begin{array}{l}\text { Uyum } \\
\text { Eksikliği }\end{array}$ & 5 & 14,16 & 14,16 & 2,83 & 2,10 & 0,217 \\
\hline $\begin{array}{l}\text { Saf Hata } \\
\text { Toplam }\end{array}$ & $\begin{array}{l}5 \\
1 \\
9\end{array}$ & $\begin{array}{c}6,74 \\
2449,23\end{array}$ & 6,74 & 1,35 & & \\
\hline $\begin{array}{l}\mathbf{R}^{2} \\
99,15 \%\end{array}$ & & \multicolumn{3}{|c|}{$\mathbf{R}^{2}$ (düzeltilmiş) } & \multicolumn{2}{|c|}{$\mathbf{R}^{2}($ tahmin $)$} \\
\hline
\end{tabular}

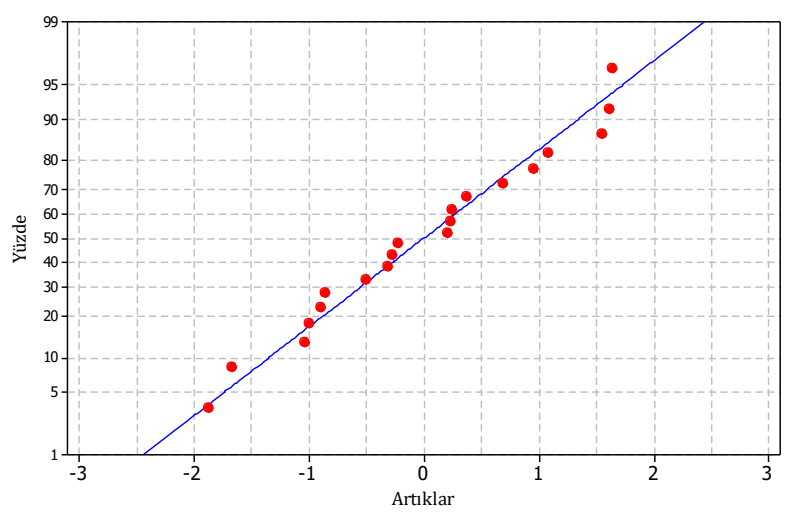

Şekil 2: Artıkların olasılık grafiği

Grafiğin analizinde artıkların ortalaması ve standart sapması 0,0 $\pm 1,049(\mathrm{n}=20)$ bulunmuştur. Normallik testlerinden biri olan $\mathrm{AD}$ testine göre $p=0,801$ bulunmuştur. Artıklar normal dağılım göstermektedir. Kompleks koaservasyon yöntemi ile enkapsülasyon işlemi için seçilen üç parametrenin (çekirdek maddesi miktarı, surfaktan konsantrasyonu, karıştırma hızı) bir fonksiyonu olarak enkapsülasyon verimliliği için bağımsız 
değişkenler ile nasıl iliş̧kili olduğu üç boyutlu yüzey grafikleri; Şekil 3'te gösterilmiştir.

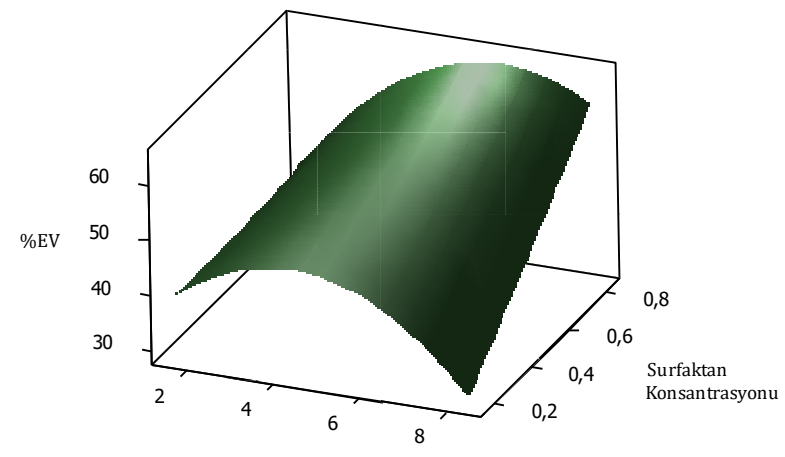

Cekirdek Madd esi Miktan

Şekil 3(a). X ekseninde çekirdek maddesi miktarı (g), Y ekseninde surfaktan konsantrasyonu $(\mathrm{a} / \mathrm{h}), \mathrm{Z}$ ekseninde \%EV'e bağlı fonksiyon grafiği.

Şekil $\quad 3(\mathrm{a}) \quad$ incelendiğinde; surfaktan konsantrasyonunun çekirdek maddesi ile birlikte artmasıyla elde edilen \%EV genellikle artmıștır.

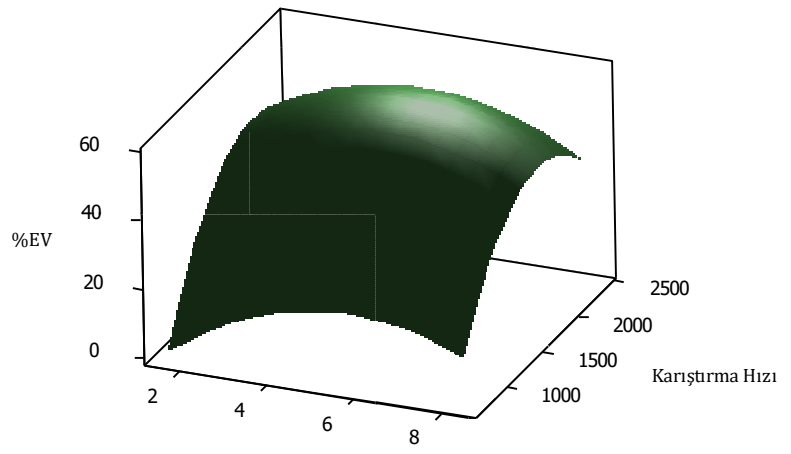

Çekirdek Maddesi Miktarı

Şekil 3(b). X ekseninde çekirdek maddesi miktarı (g), Y ekseninde karıștırma hızı (rpm), Z ekseninde \%EV'e bağlı fonksiyon grafiği.

Şekil 3(b) incelendiğinde; karıştırma hızının çekirdek maddesi miktarı ile birlikte artmasıyla elde edilen \%EV genellikle artmıștır.

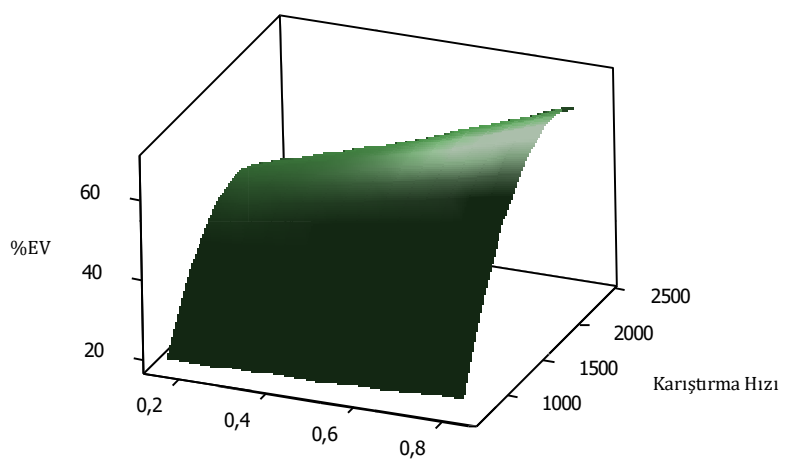

Surfaktan Konsantrasyon

Şekil 3(c). X ekseninde surfaktan konsantrasyonu (a/h), Y ekseninde karıștırma hızı (rpm), Z ekseninde \%EV'e bağlı fonksiyon grafiği

Şekil 3(c) incelendiğinde; karıştırma hızının surfaktan konsantrasyonu ile birlikte artmasıyla elde edilen \%EV genellikle artmıştır.

\subsection{Mikrokapsüllerin Morfolojik Analizleri}

Deney setindeki değișken parametreler ile üretilen numunelerdeki mikro kapsüller optik mikroskop ve SEM cihazı altında farklı büyütme oranlarında incelenmiştir. Numunelerin rastgele bir yerinden alınan 0,01 - 0,5 g aralığındaki numune cihazlarda görüntülenmiştir. Yapılan ölçümlerde kapsüller mikron ve az miktarda nanometre boyutunda ölçülmüştür. Yüksek verim alınan deneye ait bazı optik mikroskop görüntüleri Şekil 4'te gösterilmiştir.

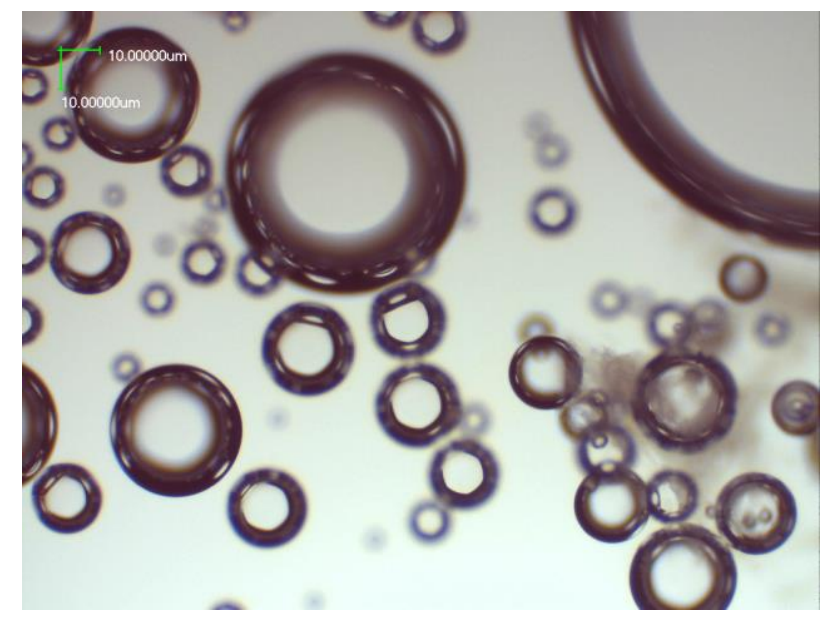

Şekil 4(a). Yüksek verimli numuneden alınan optik mikroskop görüntüsü

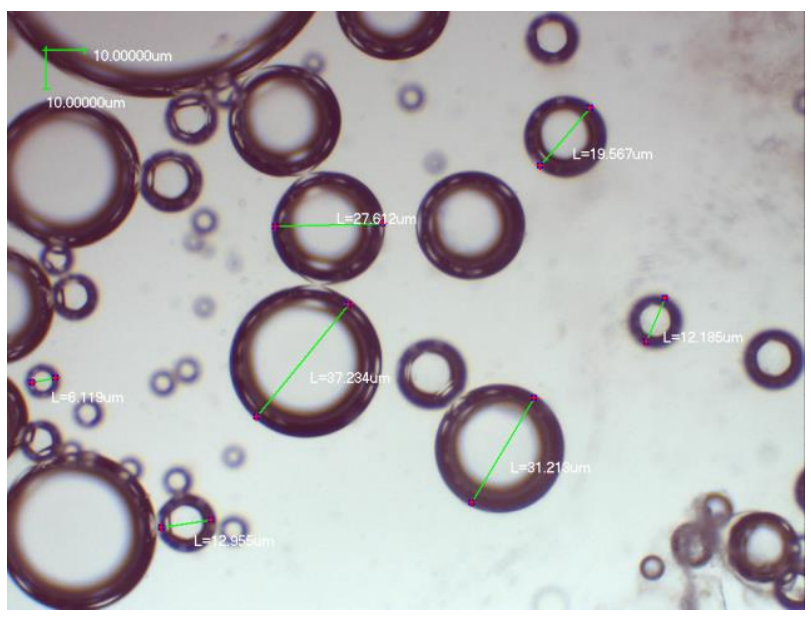

Şekil 4(b). Yüksek verimli numuneden alınan bazı ölçümleri alınmış optik mikroskop görüntüsü

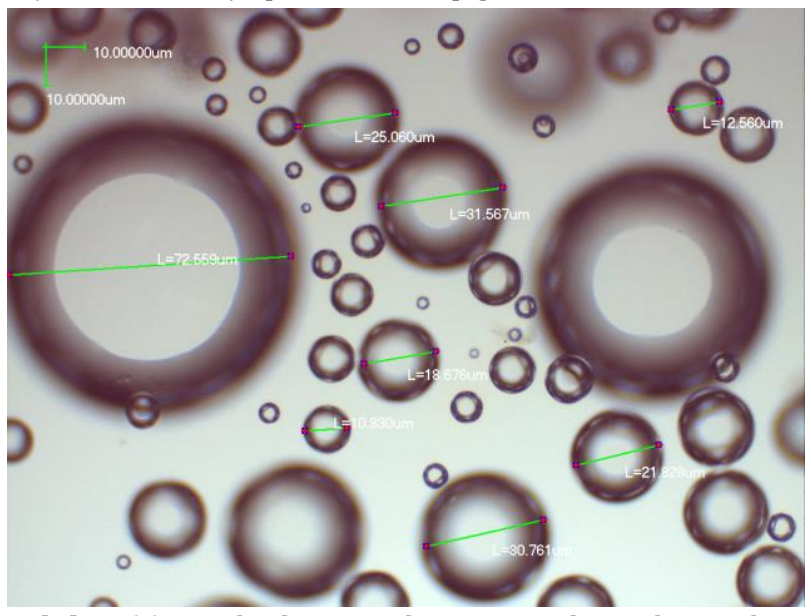

Şekil 4(c). Yüksek verimli numuneden alınan bazı ölçümleri alınmış optik mikroskop görüntüsü 
Optik mikroskoptan alınan görüntüler incelendiğinde kapsül şekillerinin düzgün, yuvarlak olduğu anlaşılmıştır. Yüksek verimli numunelerden alınan örneklere ait bazı SEM görüntüleri Şekil 5'te verilmiştir.

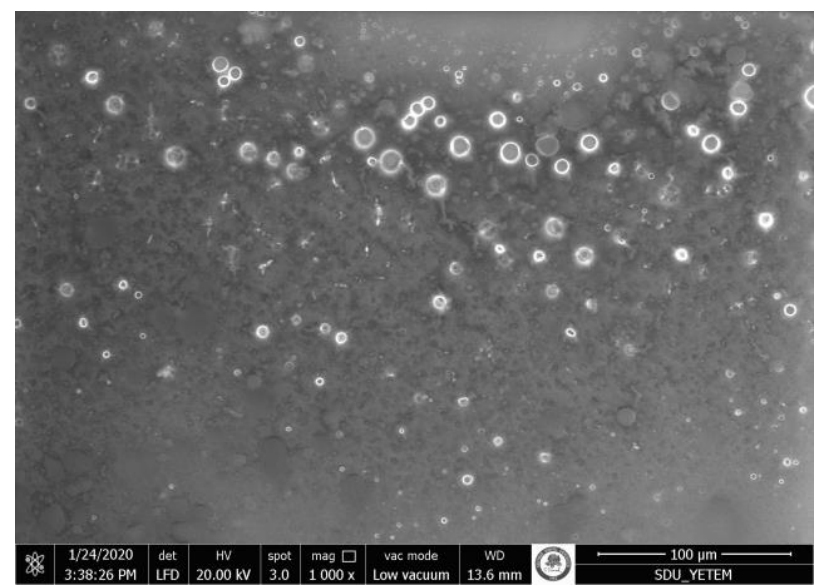

Şekil 5(a). Yüksek verimli numunenin 1000x büyütme altındaki görüntüsü

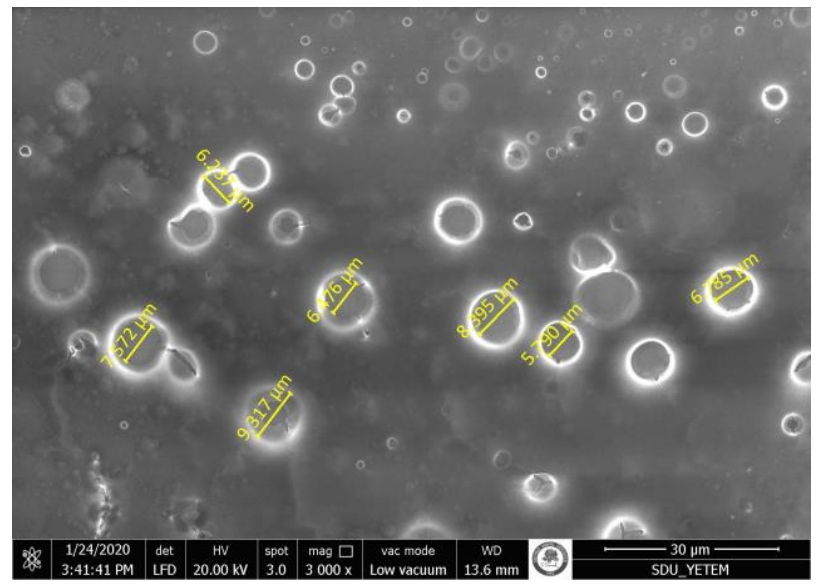

Şekil 5(b). Yüksek verimli numunenin 3000x büyütme altındaki görüntüsü

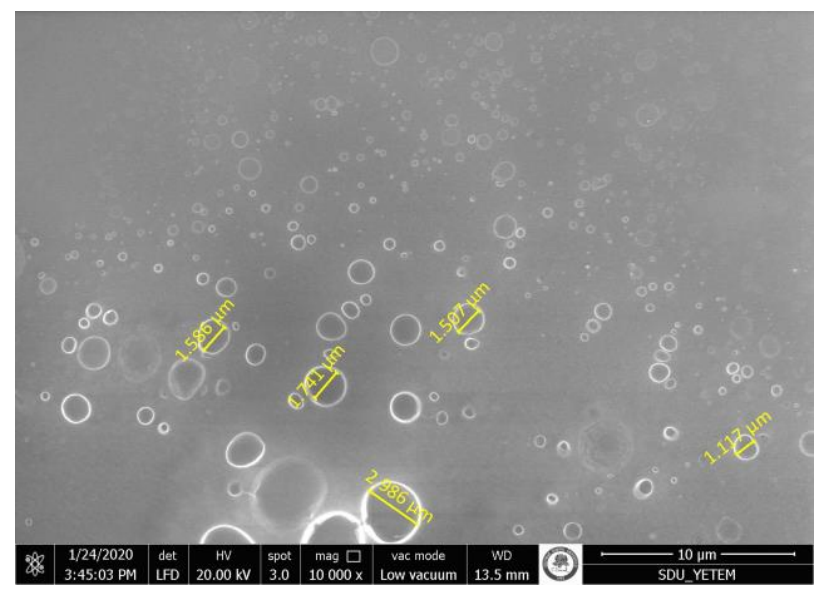

Şekil 5(c). Yüksek verimli numunenin 3000x büyütme altındaki görüntüsü

\section{Tartışma ve Sonuç}

Çalışmamızda karabaş otu yağı kompleks koaservasyon yöntemiyle üç farklı faktör ile yanıt yüzey metodolojisinde olușturulmuș yirmi adet deney ile enkapsüle edilmiştir. Deneysel sonuçları etkileyen üç faktör dışındaki tüm faktörler tüm deneyler için aynı tutulmuştur. YYM tarafından oluşturulan koşullar göz önüne alınarak üretilen tüm numuneler optik mikroskop ve SEM cihazları ile görüntülenmiş, kaydedilen görüntüleri ile yüzey morfolojik karakterizasyonları yapılmıştır. Optik mikroskop [30,31] ve SEM [21,32] görüntüleri literatürdeki benzer çalıșmalar ile yakın bulunmuștur [33]. Optik mikroskop ve SEM görüntülerinde görüntülenen kapsüllerin boyutları yardımcı programlar yardımıyla ölçülmüş ve büyük çoğunlukla mikron $(\mu \mathrm{m})$ boyutunda bulunmuștur. Sayıca az olmakla birlikte nanometre $(\mathrm{nm})$ boyutundaki nanokapsüllerede görüntülerde rastlanmıștır. Bazı SEM görüntülerinde kapsül duvarlarının parlamasının sebebinin altına koyulan lamel olduğu, gönderilen elektron demetinin lamelden geri yansiyarak kapsül kabuğuna parlaklık verdiği düşünülmektedir. Hesaplanan istatistiksel sonuçlar incelendiğinde, surfaktan konsantrasyonunun ve karıştırma hızının, çekirdek maddesi miktarı ve surfaktan konsantrasyonunun, karıștırma hizı ve çekirdek maddesi miktarının ikili olarak birlikte artmasının elde edilen verimi genellikle arttırdığı görülmüştür. Yapılan analiz sonucunda ulaşlan model önemlidir $(p<0,05)$. Bulunan $\mathrm{R}^{2}$ ve uyum eksikliği değerleri literatürde kabul gören değerler içerisindedir. En yüksek deneysel verim 7,00000 g çekirdek maddesi, surfaktan konsantrasyonu $\% 0,700000$ ve karıștırma hızı 2000,00 rpm şartlarında yapılmıș olan iki numaralı deneyde elde edilmiştir. Karabaş otu yağının jelatin/Arap zamkı duvar materyalinde kompleks koaservasyon yöntemi ile enkapsülasyonunda belirlenen üç faktöründe deneysel sonuçlarda etkili olduğu sonucuna ulașılmıștır. Tablo 4'teki uyum eksikliği ve $R^{2}$ değerleri incelendiğinde yapılan deneysel çalışmaların verim miktarları model ile verinin uyuştuğunu ortaya koymaktadır. Deneysel tasarımda kullanılan YYM yöntemi bize deneysel süreç tasarımının daha iyi açılanmasında yardımcı olmuştur. Bu da yapılacak ileriki çalıșmalarda hem karabaş otu yağı içeren mikrokapsüllerin kozmetik, gıda, ilaç gibi alanlarda farklı ürünlerde kullanılmasının hem de deneysel tasarım kullanımının kazandırdığı sonuçlar açısından faydalı olacaktır.

\section{Kaynakça}

[1] Tutin, T. G., Heywood, V. H., Burges, N. A., Valentine, D. H. (Eds.). 1964. Flora Europaea: Plantaginaceae to Compositae (and Rubiaceae) (Vol. 4). Cambridge University Press. 
[2] Carrasco, A., Ortiz-Ruiz, V., Martinez-Gutierrez, R., Tomas, V., Tudela, J. 2015. Lavandula stoechas Essential Oil From Spain: Aromatic Profile Determined By Gas Chromatography-Mass Spectrometry, Antioxidant And Lipoxygenase Inhibitory Bioactivities. Industrial Crops And Products, 73, 16-27.

[3] Tanker, M., Tanker, N., Sarer, E., Atasü, E., Sener, B., Kurucu, S., Meriçli, F. 1993. Results Of Certain Investigations On The Volatile Oil Containing Plants of Turkey. In Proceedings of an International Conference on Essential Oils for Petfumery and Flavors, Edits. KHC Baser and N. Giiler, 16-29.

[4] Adaşoğlu, N., Dinçer, S., Bolat, E. 1994. Supercritical-fluid Extraction of Essential Oil From Turkish Lavender Flowers. The Journal of Supercritical Fluids, 7(2), 93-99.

[5] Akgün, N. A., Akgün, M., Dinçer, S., Akgerman, A. 2001. Supercritical Fluid Extraction Of Lavandula stoechas L. ssp. cariensis (Boiss.) Rozeira. Journal of Essential Oil Research, 13(3), 143-148.

[6] Lawless, J. 1992. Enciclopedia Degli Olii Essenziali. Tecniche nuove. 321s.

[7] Atzei, A. D. 2003. Le Piante Nella Tradizione Popolare Della Sardegna: Documentazione Sugli Usi Alimentari, Aromatizzanti, Profumieri, Artigianali, Cosmetici, Medicinali, Veterinari, Magici, Ornamentali, Rituali, Religiosi, Tintori, Antiparassitari E Vari, Delle Piante. Delfino Carlo Editore.

[8] Angioni, A., Barra, A., Coroneo, V., Dessi, S., Cabras, P. 2006. Chemical Composition, Seasonal Variability, And Antifungal Activity Of Lavandula stoechas L. ssp. stoechas Essential Oils From Stem/Leaves And Flowers. Journal Of Agricultural And Food Chemistry, 54(12), 4364-4370.

[9] Sheikhan, F., Jahdi, F., Khoei, E. M., Shamsalizadeh, N., Sheikhan, M., Haghani, H. 2012. Episiotomy Pain Relief: Use of Lavender Oil Essence In Primiparous Iranian Women. Complementary Therapies In Clinical Practice, 18(1), 66-70.

[10] Vakilian, K., Atarha, M., Bekhradi, R., Chaman, R. 2011. Healing Advantages Of Lavender Essential Oil During Episiotomy Recovery: A Clinical Trial. Complementary Therapies In Clinical Practice, 17(1), 50-53.

[11] Kadoglidou, K., Lagopodi, A., Karamanoli, K., Vokou, D., Bardas, G. A., Menexes, G., Constantinidou, H. I. A. 2011. Inhibitory And Stimulatory Effects of Essential Oils And Individual Monoterpenoids On Growth And Sporulation Of Four Soil-Borne Fungal Isolates Of Aspergillus Terreus, Fusarium Oxysporum, Penicillium Expansum, And Verticillium Dahliae. European Journal Of Plant Pathology, 130(3), 297309.
[12] Dadalioğlu, I., Evrendilek, G. A. 2004. Chemical Compositions And Antibacterial Effects Of Essential Oils Of Turkish Oregano (Origanum minutiflorum), bay Laurel (Laurus nobilis), Spanish Lavender (Lavandula stoechas L.), And Fennel (Foeniculum vulgare) On Common Foodborne Pathogens. Journal of Agricultural And Food Chemistry, 52(26), 8255-8260.

[13] Hui, L., He, L., Huan, L., XiaoLan, L., AiGuo, Z. 2010. Chemical Composition of Lavender Essential Oil And Its Antioxidant Activity And Inhibition Against Rhinitis Related Bacteria. African Journal Of Microbiology Research, 4(4), 309-313.

[14] Wells, R., Truong, F., Adal, A. M., Sarker, L. S., Mahmoud, S. S. 2018. Lavandula Essential Oils: A Current Review of Applications In Medicinal, Food, And Cosmetic Industries of Lavender. Natural Product Communications, 13(10),

[15] Timilsena, Y. P., Akanbi, T. O., Khalid, N., Adhikari, B., Barrow, C. J. 2019. Complex Coacervation: Principles, Mechanisms And Applications In Microencapsulation. International Journal of Biological Macromolecules, 121, 1276-1286.

[16] Lam, K. H., Cheng, S. Y., Lam, P. L., Yuen, M. C. W., Wong, R. S. M., Lau, F. Y., Lai, P. B. S., Gambari, R., Chui, C. H. 2010. Microencapsulation: Past, Present And Future. Minerva Biotecnologica, 22(1), 23.

[17] Oliveira, W. D., Araújo, A. D. O., Wurlitzer, N., Bastos, M., Furtado, R. 2019. Effect of The Reaction Volume on The Formation of Microparticles of The Pequi Oil (Caryocar coriaceum Wittm.) By Complex Coacervation. Embrapa Agroindústria Tropical-Artigo Em Periódico Indexado (ALICE).

[18] Eghbal, N., Choudhary, R. 2018. Complex Coacervation: Encapsulation And Controlled Release Of Active Agents In Food Systems. Lwt, 90, 254-264.

[19] Silva, V., Rouboa, A. 2015. Combining A 2-D Multiphase CFD Model With A Response Surface Methodology To Optimize The Gasification of Portuguese Biomasses. Energy Conversion And Management, 99, 28-40.

[20] Köksal, E. 2016. Kompleks Koaservasyon Yöntemi İle E Vitamini İçeren Mikrokapsül Üretimi. Süleyman Demirel Üniversitesi, Fen Bilimleri Enstitüsü, Yüksek Lisans Tezi, 69s, Isparta.

[21] Ahn, J. H., Kim, Y. P., Lee, Y. M., Seo, E. M., Lee, K. W., Kim, H. S. 2008. Optimization Of Microencapsulation Of Seed Oil By Response Surface Methodology. Food Chemistry, 107(1), 98-105. 
[22] Hu, L., Zhang, J., Hu, Q., Gao, N., Wang, S., Sun, Y., Yang, X. 2016. Microencapsulation Of Brucea Javanica Oil: Characterization, Stability And Optimization of Spray Drying Conditions. Journal of Drug Delivery Science and Technology, 36, 46-54.

[23] Li, K., Woo, M. W., Patel, H., Selomulya, C. 2017. Enhancing The Stability Of ProteinPolysaccharides Emulsions Via Maillard Reaction For Better Oil Encapsulation In SprayDried Powders By $\mathrm{pH}$ Adjustment. Food Hydrocolloids, 69, 121-131.

[24] Ghasemi, S., Jafari, S. M., Assadpour, E., Khomeiri, M. 2017. Production Of Pectin-Whey Protein Nano-Complexes As Carriers Of Orange Peel Oil. Carbohydrate Polymers, 177, 369-377.

[25] Patrickab, K.E., Abbasa, S., Lva, Y., Ntsamacd, I.S.B., Zhanga, X. 2013. Microencapsulation By Complex Coacervation of Fish Oil Using Gelatin/SDS/NaCMC. Pakistan Journal of Food Sciences, 23(1), 17-25.

[26] Velasco, J., Marmesat, S., Dobarganes, C., Márquez-Ruiz, G. 2006. Heterogeneous Aspects Of Lipid Oxidation In Dried Microencapsulated Oils. Journal of Agricultural And Food Chemistry, 54(5), 1722-1729.

[27] Aziz, S., Gill, J., Dutilleul, P., Neufeld, R., Kermasha, S. 2014. Microencapsulation Of Krill Oil Using Complex Coacervation. Journal of Microencapsulation, 31(8), 774-784.

[28] Gören, A.C., Topçu, G., Bilsel, G., Bilsel, M., Aydoğmuş, Z., Pezzuto, J.M. 2002. The Chemical Constituents And Biological Activity Of Essential Oil Of Lavandula stoechas ssp. stoechas. Zeitschrift für Naturforschung C, 57(9-10), 797800.

[29] Öztürk, B., Konyalığlu, S., Kantarcl, G., Çetinkol, D. 2005. İzmir Yöresindeki Yabani Lavandula stoechas L. subsp. stoechas Taksonundan Elde Edilen Uçucu Yağın Bileşimi, Antibakteriyel, Antifungal Ve Antioksidan Kapasitesi. Anadolu Ege Tarımsal Araştırma Enstitüsü Dergisi, 15(1), 61-72.

[30] Mancer, D., Allemann, E., Daoud, K. 2018. Metformin Hydrochloride Microencapsulation By Complex Coacervation: Study of Size Distribution And Encapsulation Yield Using Response Surface Methodology. Journal Of Drug Delivery Science And Technology, 45, 184-195.

[31] Mendanha, D. V., Ortiz, S. E. M., Favaro-Trindade, C. S., Mauri, A., Monterrey-Quintero, E. S., Thomazini, M. 2009. Microencapsulation of Casein Hydrolysate By Complex Coacervation With SPI/pectin. Food Research International, 42(8), 1099-1104.
[32] Sharifi, F., Hadizadeh, F., Sadeghi, F., Hamed Mosavian, M. T., Zarei, C. 2016. Process Optimization, Physical Properties, And Environmental Stability of An $\alpha$-Tocopherol Nanocapsule Preparation Using Complex Coacervation Method and Full Factorial Design. Chemical Engineering Communications, 203(1), 64-74.

[33] Bayram O., Köksal E., Danaş F., Göde F., Erzengin Ö. U. 2019. A Statistical Investigation of The Effects Of Different Surfactant Concentrations On The Capsule Size In The Encapsulation Of Grapefruit (Citrus Paradisi Macf.) Peel Oil By Complex Coacervation Method. $2^{\text {rd }}$ International Health Science And Life Congress, 24-27 April, Burdur, 486-497. 